\title{
Response to a change in transport noise exposure: A review of evidence of a change effect
}

\author{
A. L. Brown ${ }^{a)}$ \\ Urban Research Program, Griffith School of Environment, Griffith University, Nathan 4111, Brisbane, \\ Australia \\ Irene van Kamp \\ Centre of Environmental Health Research, National Institute for Public Health and the Environment, P.O. \\ Box 1, 32700 BA Bilthoven, The Netherlands
}

(Received 3 April 2008; revised 8 December 2008; accepted 9 February 2009)

\begin{abstract}
Environmental appraisals of transport infrastructure plans are generally conducted in situations where there will be a step change, or an abrupt change, in noise exposure. While there has been a number of studies of response to step changes in exposure, and seven previous reviews of subsets of these studies, understanding of human response to a change in noise exposure remains limited. Building largely on these previous reviews, this paper examines the evidence that when noise exposure is changed, subjective reaction may not change in the way that would be predicted from steady-state exposure-response relationships. The weight of evidence, while not incontrovertible, is that when exposure changes, responses show an excess response compared to responses predicted from steady-state exposure-response relationships. That is, there is a change effect in addition to an exposure effect-at least for road studies and at least where the change in exposure results from changes at the source. Further, there appears to be little, if any, adaptation of this excess response with time. (C) 2009 Acoustical Society of America. [DOI: 10.1121/1.3095802]
\end{abstract}

PACS number(s): 43.50.Qp, 43.66.Lj [BSF]

Pages: $3018-3029$

\section{INTRODUCTION}

Step changes in transport noise occur in situations where (a) new roads and railways are constructed or existing ones closed; (b) there are major increases or decreases in road, rail, or air traffic; (c) noise mitigation measures are implemented in high noise environments; (d) new airport runways are constructed or existing ones closed; (e) there is a major change in the mix of road vehicle types, trucks, in particular; and where (f) there is a major rearrangements of flight paths.

These are always significant changes as far as the community, and authorities, are concerned, and a prediction of the response of the community to that change is an important part of assessment of the proposed changes.

Conventional wisdom is that human response to a step change to transport noise should be able to be predicted from exposure-response curves derived from studies where human response has been assessed over a range of noise conditions. In the past 30 years, many studies have established exposureresponse relationships for transport noise. Schultz (1978) and Fidell et al. (1991) presented synthesized curves for all such surveys for which noise exposure (as DNL) and the percentage of highly annoyed persons were available. Miedema and Vos (1998) more recently provided synthesized curves separately for aircraft, road traffic, and railway noise, adding the results of some newer studies to the data used by Schultz (1978) and Fidell et al. (1991). This synthesis also established confidence limits on the estimate of human response to transport noise exposure (Miedema and Oudshoorn,

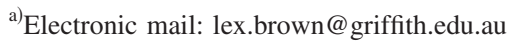

2001). The EC working group on health effects of environmental noise recommended (EC/DG ENV, 2002) the relationships presented by Miedema and Oudshoorn (2001) for estimating noise annoyance based on the noise exposure of dwellings.

However, the majority of human response measurements used in these syntheses is likely to have been conducted at sites at which the prevailing noise environment had changed little over preceding years, although we have not confirmed this by examining original site selection methodologies. Further, although again without access to sample selection methodologies, common procedures used in exposure-response studies would have been for respondents who had not been resident for a considerable period, say, a year, to be excluded from the samples, with researchers selecting these to comprise only those respondents chronically exposed to the particular noise dose of the dwellings sampled. Exposureresponse curves derived from these studies thus reflect human response to noise in situations of steady-state, constant, or unchanging noise exposure. ${ }^{1}$

These same curves are now used extensively, in noise impact assessments, to estimate likely response of a population experiencing a change in noise exposure. The interest in this paper is whether these steady-state exposure-response relationships estimate human response to a change.

There is continuing interest in response to change (Anotec Consulting, 2003; Huybregts, 2003; Guski, 2004; Van Kempen and van Kamp, 2005; Klæboe et al., 2006). Driving much of this interest is the predicted growth in land and surface traffic, the new infrastructure to accommodate this growth, and community response and health effects associ- 
ated with these changes (for example, Egan et al., 2003). There is rapid growth in traffic at regional airports, and new runways are being planned at major EU airports such as Frankfurt, Schiphol and Heathrow, and throughout Asia.

There is now a number of studies that have examined human response where there has been a step change, or abrupt change, in noise exposure. The results suggest, although not invariably, that response may be different where there has been an increase or decrease in level, to that predicted from steady-state curves. In other words, human response to change in exposure may include a change effect as well as an exposure effect and the change effect manifests itself as an excess response.

Previously, excess response has been described by various terms such as exaggerated response (Huybregts, 2003), over-reaction (Fields, 1993; Job, 1988; Schreckenberg and Meis, 2007; Breugelmans et al., 2007), or overshoot (Guski, 2004). Lambert et al. (1998) used the term new infrastructure effect. However, in the psychological literature, overreaction is defined as an exaggerated response or a reaction with unnecessary or inappropriate force, emotional display, or violence. We suggest that terms that carry such connotations be abandoned in favor of the more neutral excess response, replacing all of the above. ${ }^{2}$ Kastka et al. (1995a) and Baughan and Huddart (1993) previously used a related term, excess effects. There are also a few reports in the change literature where the opposite of excess response has been observed, and while it is not a completely satisfactory antonym to excess response, we suggest that these observations be described as an under response to change in exposure.

This paper reviews the literature of studies of human response in situations where the level of transportation noise has changed. Past overviews, individual studies, and more recent results were examined, and we summarize in this paper the weight of evidence available on the existence, magnitude, and persistence of the change effect. In a companion paper (Brown and van Kamp, 2009), we examine the range of explanations that have been suggested for the excessresponse phenomenon.

\section{THE CHANGE LITERATURE}

We examined the scattered, but growing, literature on human response to a change in noise exposure. Some 140 papers were located in a search of the literature, 1980-2006, including Psycinfo, Toxline, Embase, Medline, SciSearch, Biosis, and Enviroline. The search profile included keyword(s), in title and or abstract, related to noise, change, sensitivity, annoyance, and (over-) reaction. In addition, titles were selected from previous reviews of response to change and Internoise Proceedings (1985-2007). From the initial list, a selection process excluded studies where the noise source was not transport (road, air, or rail), the subjects were specific groups (e.g., the hearing impaired), the sounds were highly specific (e.g., sonic booms), or where there was no observed change in noise levels. Outcome measures were restricted to dissatisfaction, annoyance, nuisance, and activity interference/disturbance, or sleep indicators; studies of performance (e.g., in schools) were excluded. Laboratory studies were also excluded, as were studies that reported change in exposure but without reporting response.

Many investigations were reported in more than one paper; multiple studies were sometimes reported in a single paper; and several were re-analyzed and re-reported by several authors. We have chosen not to separate out these matters, but include in the tables below a set of some 40 papers which contain within them the body of studies and prior reviews on human response to a step-change in transport noise exposure over the past 3 decades.

\section{THE STUDIES}

\section{A. Summary of the studies}

Tables I and II provide an overview of the studies located. Over 20 papers (Table I) involved a decrement in exposure, more than 10 an increment in exposure (Table II), and 7 include both increments and decrements. Within the tables, studies have been ordered chronologically and it can be seen that there has been modest, though consistent, interest in the field over more than 3 decades. The tables contain a simple summary of the nature of the change in exposure (cause of the change and approximate magnitude of the change in level when reported) and the survey design - most involving before and after surveys, some also including control sites. The tables also indicate, where available, select observations on measured change effects: excess response or otherwise in community response to change, and adaptation of any excess response over time, although of course the observations from most studies are far more complex than what is able to be shown in this table. They show diverse and sometimes conflicting findings in the various studies.

The search of the change literature found seven prior reviews of these studies of change. Several were particularly detailed in their examination of work to date and provide an excellent foundation for examining the change literature. Most of these had, however, appeared only in the gray literature, and it is appropriate, given their limited dissemination, to summarize the key outcomes of the prior reviews below, then updating these with the findings of more recent studies where possible. The tables show the individual studies included in each of the earlier reviews.

\section{B. Some characteristics of change studies}

The studies involved road, air, and rail sources, although not equally, with well over half involving changes in road traffic noise levels, and about one-quarter air transport sources and the rest rail. Residents' responses to noise were those that occurred in their dwellings, although several of the more recent studies included additional responses outdoors.

\section{Type of change}

A step, or abrupt, change in noise exposure may occur through three different mechanisms. Type 1 changes result from a new or eliminated source, or change in intensity of the source. The majority of the studies (all of the air studies) were Type 1, resulting from changes in traffic flow rates, road bypass construction, or change in runway configura- 
Reviews

Reference

SS FEZ

S HU Noise change

Survey design

Select observations

Lambert, 1978

$\begin{array}{cccc}\text { Air } & 1 & & \\ \text { Road } & 2 & \text { F } & \text { H }\end{array}$

$\mathrm{H}$

FEZ

Fath change, $-3 \mathrm{~dB}$

Kastka and Paulsen, 1979

Road 2

$\mathrm{H}$
$\mathrm{H}$

Kastka, 1981

Immed B, immed. A+1 mo. A

No reduction in effects

Mackie and Davies, 1981

Road 1

V H

FEZ

7 sites barrier, -3 to -18 (mean $-7 \mathrm{~dB})$

5 mo. B, 17 mo. A, + retro

No excess response

$\begin{array}{lllll}\text { Mackie and Davies, 1981 } & \text { Road } & 1 & \text { F } & \text { H } \\ \text { Langdon and Griffiths 1982 } & \text { Road } & 1 & \text { F } & \text { H }\end{array}$

Richard and Richter-Richard, 1984 Road

Brown et al., 1985

F $\quad H \quad S S$

sites traffic -8 to 3 (mean $-1 \mathrm{~dB}$ )

yr $\mathrm{B}, 1$ yr A

Under response -but see Kastka et al. (1995a)

$\sim 1 \mathrm{yr} \mathrm{B}, 1 \mathrm{yr} \mathrm{A}$

management, -3 to $-5 \mathrm{~dB}$

B, 3-6 mo. A

6 bypass sites -3 to $-15 \mathrm{~dB}$

3 mo. B, 4-6 mo. A

18 sites traffic calming to -12 (mean $-3 \mathrm{~dB}$ ) B, 6 mo. A

Mostly excess response, variable across sites

Babisch and Gebhardt, $1986 \quad$ Road $1 \quad$ SS

Griffiths and Raw, 1989

1 site traffic reduction $-10 \mathrm{~dB}$

15 mo. A, retrospective

see Langdon, Griffiths, 1982

Excess response

Excess response,

Excess response

. No excess response in disturbances

17-22 mo. A, 7-9 yr A

1 mo. B, 1 mo. A

$\mathrm{H}$

Kastka et al.,1995b

Öhrström, 1997

Moehler et al., 1997

Mital and Ramakrishnann, 1997

Klæboe et al., 1998

Mehra and Lutz, 2000

$S$ FEZ $S$ Continution of previous studies

sfeld et al., 2001

Öhrström, 2004

Continuation of
Barrier $-9 \mathrm{~dB}$

$1-2$ yr B, 8-10 yr A

12 sites barriers 0 to -13 (mean $-4 \mathrm{~dB}$ )

Airport source reduction $-1.5 \mathrm{~dB}$

2 yr A gradual change

$\mathrm{S} \quad$ Various countermeasures + new traffic

$\mathrm{B}, 3.5 \mathrm{yr} \mathrm{A}$

SS

HU Rail grinding source reduction -7 to $-8 \mathrm{~dB} 1 \mathrm{mo}$. B, 1 and $12 \mathrm{mo}$. A

Not reported

SS

1 barrier site

$\mathrm{B}, 7$ and 9 yr A

$\mathrm{B}, 3$ yr A, retrospective

2-3 mo. B, 14 mo. A

Bypass relief of urban area

Bypass tunnel, -9 to $-14 \mathrm{~dB}$

S Town traffic relief, bypass -2 to $-4 \mathrm{~dB}$

6 mo. B, 7-9 mo. A

See Öhrström and Skånberg, 2000) 2-3 mo. B, 14 mo. A

No $(22$ mo.) some $(7 \mathrm{yr})$ adaptation

Noise was not the only environmental change

Under and excess response, No adaptation

Not noticed by community

Expectation possibly influences annoyance

No estimate of change effect

Inadequate data on response

Excess response

No estimate of change effect

No excess response

Noise change too small for annoyance changes

9 mo. B, 15 mo. A

No excess response $\mathrm{a}^{\mathrm{a}}$, No adaptation

Excess response outdoors, not indoors ${ }^{\mathrm{a}}$

(1 below.

But see contrary evidence in Fig. 1 below.

$\mathrm{B}=$ before change, $\mathrm{A}=$ after change, $\mathrm{mo} .=\operatorname{month}(\mathrm{s}), \mathrm{yr}=$ year(s), wk=week $(\mathrm{s})$, and $\sim=$ approximately.

Reviews: F: Fields (1994); V: Vallet (1996); H: Horonjeff and Robert (1997); SS: Schuemer and Schreckenberg (2000); FEZ: Fields et al. (2000); S: Stansfeld et al. (2001); HU: Huybregts (2003), 
TABLE II. Change studies in which there was an increase (or an increase and a decrease) in noise exposure.

\begin{tabular}{|c|c|c|c|c|c|c|c|c|c|c|c|c|}
\hline \multirow[b]{2}{*}{ Reference } & \multirow[b]{2}{*}{ Source } & \multirow[b]{2}{*}{ Type } & \multicolumn{7}{|c|}{ Reviews } & \multirow[b]{2}{*}{ Noise change } & \multirow[b]{2}{*}{ Survey design } & \multirow[b]{2}{*}{ Select observations } \\
\hline & & & $\mathrm{F}$ & $\mathrm{V}$ & $\mathrm{H}$ & SS & FEZ & $\mathrm{S}$ & $\mathrm{HU}$ & & & \\
\hline Jonsson and Sörensen, 1973 & Road & 1 & $\mathrm{~F}$ & & $\mathrm{H}$ & & & & & New highway, increase not reported & 6 mo. A, 18 mo. A & No adaptation \\
\hline Nimura et al., 1973 & Rail & 1 & $\mathrm{~F}$ & & $\mathrm{H}$ & & & & & Shinkansen, 2 different lines & 8 yr A one line, 4 mo. A other & $\begin{array}{l}\text { Difference between lines } \\
\text { implies adaptation }\end{array}$ \\
\hline Weinstein, 1982 & Road & 1 & $\mathrm{~F}$ & & $\mathrm{H}$ & SS & & & & New road, $+19 \mathrm{~dB}$ & B, 4 and 16 mo. A. Controls & No adaptation \\
\hline Van Dongen and van den Berg, 1983 & Rail & 1 & & & $\mathrm{H}$ & SS & & & $\mathrm{HU}$ & New line & 2 mo. B, 4 mo.A, 18 mo. A & $\begin{array}{l}\text { Excess response, some } \\
\text { adaptation lower levels }\end{array}$ \\
\hline Fidell et al., $1985^{\mathrm{a}}$ & Air & 1 & $\mathrm{~F}$ & & $\mathrm{H}$ & & FEZ & & & Temporary flight changes, +9 to $-19 \mathrm{~dB}$ & B, weekly A approx, 5 rounds & $\begin{array}{l}\text { Excess response (Raw and } \\
\text { Griffiths, } 1985 \text { reanalysis) }\end{array}$ \\
\hline Raw and Griffiths, 1985 & Air & 1 & $\mathrm{~F}$ & & $\mathrm{H}$ & SS & & & & Reanalysis of Fidell et al. (1985) & See Fidell et al., 1985 & Excess response \\
\hline Griffiths and Raw, $1986^{\mathrm{a}}$ & Road & 1 & $\mathrm{~F}$ & & $\mathrm{H}$ & SS & FEZ & $\mathrm{S}$ & & 6 bypass 1 new road, $\min +/-3 \mathrm{~dB}$ & $1-4$ mo. B, 2-3 mo. A & Excess response \\
\hline Brown, 1987 & Road & 1 & $\mathrm{~F}$ & & $\mathrm{H}$ & SS & & & & 1 site traffic increase +6 to $-11 \mathrm{~dB}$ & $2 \mathrm{wk} \mathrm{B}, 2-7$ mo. A, $12 \mathrm{mo} . \mathrm{A}$ & Excess response, no adaptation \\
\hline Baughan and Huddart, $1993^{\mathrm{a}}$ & Road & $\cdots$ & & & $\mathrm{H}$ & & & & & 9 decrease 4 increase -10 to $+5 \mathrm{~dB}$ & $1-2$ mo. B, 1-2 mo. A & Excess response, \\
\hline Gjestland et al., 1995 & Air & 1 & & & & & FEZ & & & Temporary flight changes for $3 \mathrm{wk}$ & $\mathrm{B}$, during, $\mathrm{A}$ & No response to temporary increase \\
\hline Job et al., $1996^{\mathrm{a}}$ & Air & 1 & & & & & & & & New runway, likely changes only & B only, + expectation of change & Attitude influences reaction \\
\hline Lambert et al., 1994, 1996 & Rail & 1 & & $\mathrm{~V}$ & & & & S & & New TGV line-increases unreported & $3-4$ yr A & $\begin{array}{l}\text { Excess response, adaptation } \\
\text { lower levels }\end{array}$ \\
\hline Fidell et al., 1996 & Air & 1 & & & & SS & FEZ & & & Gradual decrease over $3 \mathrm{yr}-3 \mathrm{~dB}$ & Cross-sectional at end of period & $<10 \%$ noticed change \\
\hline Lambert et al., 1998 & Various & 1 & & & & & & & $\mathrm{HU}$ & Change as a result of new infrastructure & $\begin{array}{l}\text { Compare responses beside infrastructure } \\
<5 \mathrm{yr} \text { and }>10 \mathrm{yr}\end{array}$ & $\begin{array}{l}\text { Change effect for roads, } \\
\text { change effect for railways above } 67 \mathrm{~dB}\end{array}$ \\
\hline $\begin{array}{l}\text { Hatfield et al., } \\
\text { 1998a } \text {; Hatfield } \text { et al.,1998b }{ }^{\text {a }}\end{array}$ & Air & 1 & & & & & & & & New runway, increases and decreases & $\mathrm{B}$, separate group A & Some excess response (home owners) \\
\hline Fidell et al.,2000 & Air & 1 & & & & & & & & Airport closure and opening 3 airports & behavioral awakening $\mathrm{B}$ and $\mathrm{A}$ & No changes observed \\
\hline Hatfield et al., 2001 ${ }^{\text {a }}$ & Air & 1 & & & & & & & & New runway & $1-3$ mo. A & $\begin{array}{l}\text { No change effect, self-reported } \\
\text { adaptation }\end{array}$ \\
\hline Schreckenberg et al., 2001 & Rail & 1 & & & & & & & $\mathrm{HU}$ & Existing line $+0 \mathrm{~dB}$, new not yet built & $1 \mathrm{yr} \mathrm{B}, 1 \mathrm{yr} \mathrm{A}$ & Expected future annoyance high \\
\hline Fidell et al., 2002 & Air & 1 & & & & & & & & New runway, 0 to $+7 \mathrm{~dB}$ & 15 mo. B, 21 mo. A & $\begin{array}{l}\text { Excess response, not all attributable } \\
\text { to change }\end{array}$ \\
\hline & & & & & & & & & & & & $\begin{array}{l}\text { Excess response for increase, } \\
\text { not for decrease. Excess } \\
\text { response is not explained by }\end{array}$ \\
\hline Breugelmans et al., $2007^{\mathrm{a}}$ & Air & 1 & & & & & & & & $\begin{array}{l}\text { New runway Schiphol. Increases to }+4 \mathrm{~dB} \text {, } \\
\text { decreases to }-6 \mathrm{~dB} \text { (mean levels) }\end{array}$ & $\begin{array}{l}\text { Panel study. B, and } 3 \text { A at yearly intervals. } \\
\text { Control Group }\end{array}$ & $\begin{array}{l}\text { non-acoustical factors } \\
\text { Generally no adaptation after } 21 / 2 \mathrm{yr}\end{array}$ \\
\hline
\end{tabular}

${ }^{\mathrm{a}}$ These studies also included sites at which there was a decrease in noise exposure.

$\mathrm{B}=$ before change, $\mathrm{A}=$ after change, $\operatorname{mo} .=\operatorname{month}(\mathrm{s})$, wk $=$ week $(\mathrm{s}), \mathrm{yr}=\mathrm{year}(\mathrm{s})$, and $\sim=$ approximately

Reviews: F: Fields (1994); V: Vallet (1996); H: Horonjeff and Robert (1997); SS: Schuemer and Schreckenberg (2000); FEZ: Fields et al. (2000); S: Stansfeld et al. (2001); HU:Huybregts (2003). 
tions. Type 2 changes result from some (usually noise path) mitigation intervention. In Type 2 changes, there are no changes in the transport source flow rates or source noise emissions, just in exposure of the respondents. All of the Type 2 studies involved barriers, mostly along roads-one along a railway. Over three quarters of all change studies were Type 1 . There could also be a Type 3 change in which an individual may relocate from one dwelling to another that has a different noise exposure. While this, equally, is a stepchange in noise exposure, this type of change was not reported in any of the studies reviewed, though it might usefully be included in future studies seeking to investigate the nature of human response to change.

\section{The change in noise exposure}

Dimensions of the change in exposure include the direction of the change-increase or decrease, the magnitude of the change, and whether the change is a step change (say, from one day to the next) or whether it is gradual, and if gradual the rate of change-over several weeks, or over, say, a year. Some noise exposure changes may be temporary (such as shutting a runway for maintenance) whereas others are "permanent." Some studies of gradual and of temporary change are included in the studies in Tables I and II, but the majority was step changes.

Different studies used quite different noise metrics, but always those conventionally used to describe noise exposure from the particular transport sources. Indicative changes in level, to the extent that these can be summarized from the original studies, are shown in Tables I and II, with changes reported in decibels, irrespective of the specific noise metric used [in line with the approach suggested by Fields (1990)]. Many of the studies involved substantial change $(5 \mathrm{~dB}$ or more), though some reported considerably less change, even purporting to be studies of change when accompanied by small changes of $2 \mathrm{~dB}$ or less. Part of the conflicting results from different studies of change may result from bundling together the results of studies in which the change in level has been large, and others where the change has been minimal and potentially non-noticeable by respondents.

\section{Measures of response}

The subset of the literature chosen was that reporting outcomes in terms of dissatisfaction, annoyance, and activity interference (disturbance) including self-reported sleep disturbance measures. The majority of change studies focused on self-reported annoyance/dissatisfaction. Given that most of the studies were conducted before the development of the ISO standard on measuring annoyance (ISO, 2001), they contain different approaches, scales, and measures in the reporting of human response.

\section{Study designs}

Some change studies have been cross-sectional, comparing results at change sites to those at control sites or against general exposure-response curves. However, most are longitudinal, involving either simple before and after designs, where exposure and response are measured at two points of time, or periodically over a much longer period out to several years after the change. Not all studies have been able to undertake measurements before the change occurred and retrospective assessments (recall) of prior situations have occasionally been utilized, as have assessment of respondent's expectation of the post-change situation.

\section{The contexts}

There are various contexts in which changes in noise occur. In addition to the major distinction between Type 1 and Type 2 changes, important contextual dimensions include the following: whether respondents knew the change to be permanent or temporary; whether the change occurred with, or immediately following, periods of intensive construction activities; the reason for the noise change; and the activities and attitudes of the authorities responsible for the change. Some noise changes, for example, may occur in contexts in which the authorities are seen to attempt to manage, minimize, or explain the change; others may occur without such interventions. Change situations may also involve community concern or protests over the matters which generated the change in noise exposure. These contextual matters are not examined further in the current paper, but are considered in a review of explanations postulated for the change effect (Brown and van Kamp, 2009).

\section{PREVIOUS REVIEWS OF CHANGE STUDIES}

The seven prior reviews were conducted by Fields (1994), Vallet (1996), Horonjeff and Robert (1997), Schuemer and Schreckenberg (2000), Stansfeld et al. (2001), Fields et al.. (2000) and Huybregts (2003). Purpose, methodology, and comprehensiveness of these reviews varied.

Fields (1994) conducted a meta-analysis on 282 studies of community reaction to environmental noise, examining the effect of personal and what he called situational variables on reported effects of noise. A subset of these studies involved a change in noise exposure. Fields (1994) tested specific hypotheses: whether a new noise or a change in noise impacted annoyance more than would be predicted from reactions to a familiar, existing noise (excess response) and whether annoyance decreased as the time since an increase in noise level lengthened (adaptation of the change effect). His results are shown in Tables III and IV. In Table III, change in exposure was present in 14 of the studies he reviewed (for which there were 19 researcher findings included in the analysis). Of the 19 findings, 8 concerned airports.

Fields (1994) concluded, from the studies he reviewed, that the evidence was too unevenly divided to indicate whether changes in noise cause excess response to the change. While excess response was observed in $42 \%$ of the findings (32\% of responses), under response was observed in $11 \%$ (34\% of the responses), with the remainder showing no important difference. When the analysis included only standard surveys, the majority (some $60 \%$ of findings and responses) indicated excess response. The studies included increases in exposure as well as decreases, and Fields (1994) separately examined these, concluding that there was not a 
TABLE III. Results of Fields (1994) meta-analysis examining community reaction to a change (increase or decrease) in noise exposure. "Findings" relate to observation by the original researchers, and "interviews" to the total number of respondents.

\begin{tabular}{|c|c|c|c|c|c|}
\hline \multirow[b]{2}{*}{ Type of findings } & \multirow[b]{2}{*}{$\begin{array}{l}\text { Findings or } \\
\text { interviews }\end{array}$} & \multirow[b]{2}{*}{$\begin{array}{l}\text { Number of } \\
\text { findings } \\
\text { or interviews }\end{array}$} & \multicolumn{3}{|c|}{$\begin{array}{l}\text { Percent of findings or interviews that } \\
\text { show when the noise exposure changes }\end{array}$} \\
\hline & & & $\begin{array}{l}\text { Respondents } \\
\text { under-react } \\
\text { to a change }\end{array}$ & $\begin{array}{l}\text { No important } \\
\text { difference }\end{array}$ & $\begin{array}{c}\text { Respondents } \\
\text { over-react } \\
\text { to a change }\end{array}$ \\
\hline \multirow[t]{2}{*}{ Standard and nonstandard ${ }^{\mathrm{b}}$} & Findings & 19 & $11 \%$ & $47 \%$ & $42 \%$ \\
\hline & Interviews/responses & 14097 & $34 \%$ & $35 \%$ & $32 \%$ \\
\hline \multirow[t]{2}{*}{ Standard only } & Findings & 13 & $8 \%$ & $31 \%$ & $61 \%$ \\
\hline & Interviews/responses & 7737 & $11 \%$ & $29 \%$ & $60 \%$ \\
\hline
\end{tabular}

${ }^{\mathrm{a}}$ We use the term of Fields (1994) over-react (and under-react) rather than our preferred terms excess response (and under response) in this table.

${ }^{\mathrm{b}}$ Nonstandard studies were those which the author had classified as having some methodological weakness.

clear pattern distinguishing between the results where there were increments or decrements in noise exposures.

Following a change in noise exposure, the meta-analysis also found mixed evidence as to whether the levels of annoyance with the new levels of exposure decreased (adapted) over time. Table IV shows that while $43 \%$ of findings $(49 \%$ of the response) show such adaptation, $43 \%$ of findings (13\% of the responses) showed the opposite-annoyance increased over time since the change-and the remainder showed no increase or decrease.

Vallet (1996) did not undertake a similar systematic review of studies of change, instead making a series of observations, mostly from airport noise studies, on the effects of change and the methodology of change studies. Our paraphrasing of his observations is as follows.

- Annoyance shows some inertness to the physical change in levels both for gradual change (gradual increase as traffic loads increased or gradual decrease as noise emission levels of individual aircraft decreased) and for step changes such as new airports or runways. He suggested, though on what evidence is unclear, that a minimum of $6 \mathrm{dBA} L_{\mathrm{eq}}$ of the noise exposure is necessary before there is a change in the annoyance level.

- Physiological measures showed a larger and quicker response to the change than did annoyance, where there was a time delay in a decrease in annoyance (at Los Angeles) and a clear excess response to new aircraft noise (in Paris).

- Non-acoustical variables such as fear, noise sensitivity, attitudes toward the source, belief that authorities could pre- vent or reduce the noise, and advertising campaigns all influence the noise response and need to be investigated in change studies.

Horonjeff and Robert (1997) undertook an extensive review, building largely on the work of Fields (1994), identifying 23 change studies in 51 citations, covering road (12 studies), rail (2), and air (9) transport sources. The purpose of their review was as precursor to the design of further studies to develop a predictive model for the effect of change in noise exposure around airports, and included a detailed examination of the purpose, methodology, results, and limitations in the studies conducted to that time. Of particular interest was their synthesis of the magnitude of any change effect measured in the studies they reviewed. Such a synthesis required them to make approximations (described in the original paper) to overcome the difficulties presented by different acoustic measures, response scales, and available baseline $^{3}$ responses from which to estimate the change effect. This analysis by Horonjeff and Robert (1997) is a pivotal review as it contains quantitative estimates of excess response in the change studies. We report their analysis of excess response below, and add newer data to it from studies conducted since their review.

The Horonjeff and Robert (1997) synthesis was in terms of a decibel-equivalent estimate (see Fields, 1990) of the magnitude of the change effect-what they called the abrupt-change effect. The decibel-equivalent change effect is the change, in decibels, on the exposure-response curve, ad-

TABLE IV. Results of Fields (1994) meta-analysis examining whether annoyance with a new source increases with time after an increase in noise exposure.

\begin{tabular}{llcccc}
\hline \hline & & & \multicolumn{2}{c}{$\begin{array}{c}\text { Percent of findings or interviews that } \\
\text { show when the noise exposure changes }\end{array}$} \\
\cline { 5 - 6 } Type of findings & $\begin{array}{l}\text { Findings or } \\
\text { interviews }\end{array}$ & $\begin{array}{c}\text { Number of } \\
\text { findings } \\
\text { or interviews }\end{array}$ & $\begin{array}{c}\text { Annoyance } \\
\text { increases }\end{array}$ & $\begin{array}{c}\text { No important } \\
\text { difference }\end{array}$ & $\begin{array}{c}\text { Annoyance } \\
\text { decreases }\end{array}$ \\
\hline Standard and nonstandard & Findings & 7 & $43 \%$ & $14 \%$ & $43 \%$ \\
Standard only & Interviews/responses & 1581 & $13 \%$ & $38 \%$ & $49 \%$ \\
& Findings & 6 & $33 \%$ & $17 \%$ & $50 \%$ \\
\hline \hline
\end{tabular}




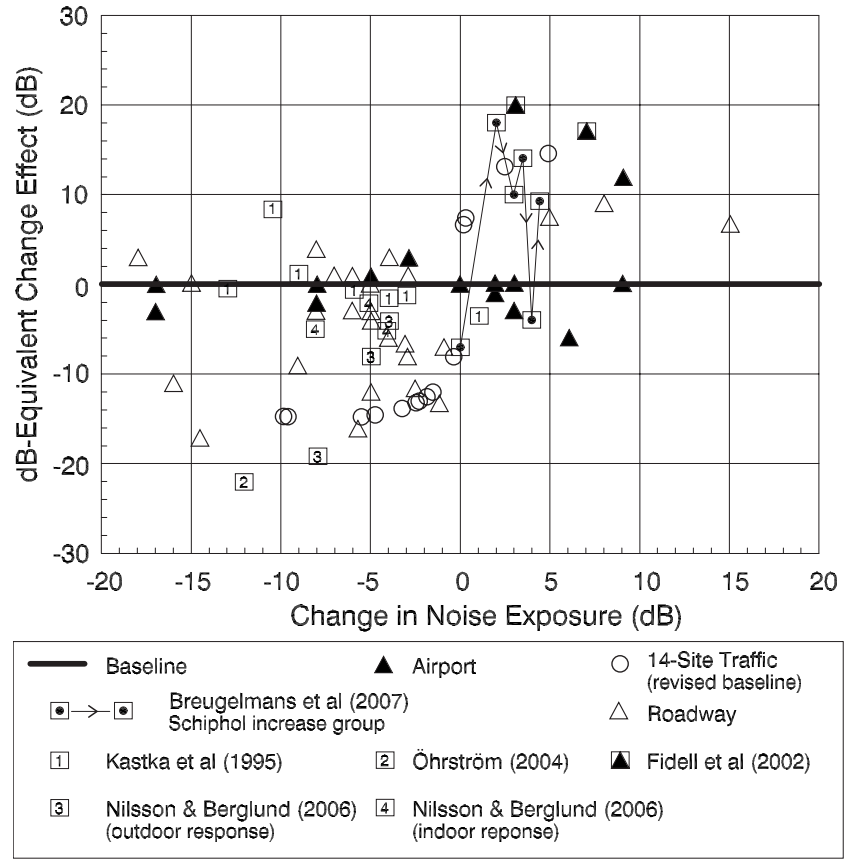

FIG. 1. Decibel-equivalent change effect (excess response) for different levels of change in noise exposure. Most of the data points are from the original review by Horonjeff and Robert (1997). The data points plotted with square symbols have been added by the present authors from more recent studies-see Sec. V. The line with arrows connects the data points tracing the trajectory of excess response of one panel over $2 \frac{1}{2}$ years (six remeasurements) following an increase in aircraft noise at Schiphol airport (Breugelmans et al., 2007) — and was also added by the present authors. Most of the studies (first and third quadrants) indicate an excess response, though a few (second and fourth quadrants) show the opposite-an under response to the change. (after Horonjeff and Robert, 1997).

ditional to the before to after change in exposure, which would predict the change in response between the before and after conditions. Their synthesis is shown in Fig. 1 [which included adjusting the baseline used in one study: the 14-Site Traffic study of Baughan and Huddart (1993)]. Figure 1 shows the change in exposure on the horizontal axis $(-18$ $\mathrm{dB}$ decreases to $+15 \mathrm{~dB}$ increases) and the decibelequivalent change effect on the vertical axis. In the words of Horonjeff and Robert (1997):

Data points that lie along the horizontal axis $(0 \mathrm{~dB}$ Equivalent change effect) indicate cases in which the baseline dose-response curve for the study correctly estimates the change in annoyance: no abrupt change in effect was observed....

Data points in the first and third quadrants ... indicate cases in which there was an abrupt-change effect, and the effect resulted in a change in annoyance greater than that predicted from the baseline curve.

Figure 1 shows that much of the data falls into the first and third quadrants, that is, the majority of results support the existence of an excess-response change effect. There are no data points representing a strong under response, while there are large excess responses to small level changes of 1-2 dB. Results from more recent studies (see Sec. V below) are also plotted in this figure.
Horonjeff and Robert (1997) also found that nine studies designed to measure the decay of the excess response generally failed to find evidence of decay, that is, there was little evidence of adaptation or habituation of the change effect. Most first post-change interviews were conducted 3-7 months after the change (one at 0.5 months, and one at 12 months), with last post-change interviews conducted 16-96 months after the change. There is no supporting evidence that excess response attenuates with time.

Horonjeff and Robert (1997) drew an extensive set of conclusions with respect to methodology for change studies - among which is that it is critical that change studies need to be longitudinal as it is difficult to base any conclusions about change on cross-sectional studies. They also noted the need for site-specific baseline exposure-response curves and for accounting for the possible influence of mediating variables (such as the specific neighborhood, demographic variables, attitudes, and expectations of the respondents concerning the noise source).

Schuemer and Schreckenberg (2000) reviewed 14 of what they termed exemplary studies on step changes in transport noise. They concluded the following.

- In ten studies an excess response to change in noise levels was confirmed-for both incremental and decremental noise changes.

- There was no evidence of adaptation of the excess response.

- The authors also noted that the characterization of a change as before and after may be simplistic, identifying that most situations are more likely to have several different before situations (for example, before announcement, after announcement, and construction) and after situations (immediately upon change, days or weeks after, and years after).

Fields et al. (2000) reported a rigorous analysis of previous studies and reviews of change that was aimed at developing tools to design further studies to estimate the stepchange effect in community response to a change in noise levels, particularly for airports. They made a large number of recommendations and observations, and only a selection of these is reported here.

- Several previous studies of changes in noise environments have been conducted where the changes in exposure were too small to have a reasonable probability of being detected (e.g., Fidell et al., 1985 and Gjestland et al., 1990). They suggested that almost nothing can be learnt about the effects of change unless those changes involve considerable changes in noise exposure;

- Permanent changes are likely to produce different reactions to temporary changes [for example, temporary runway closure for repairs (Fidell et al., 1985) and short-term military exercises (Gjestland et al., 1995)].

- Response to changes in source levels may be quite different to change effects generated by path attenuation (house insulation or barrier construction);

- Other mediating variables that affect annoyance can be spatially or temporally correlated with the noise change 
and can distort measures of the effect of change. Both cross-sectional studies and longitudinal studies have problems in isolating the change effect, with longitudinal studies preferred utilizing repeat measures of the same subjects, though with the need to control for the correlated variables to the maximum extent possible.

- Evidence is presented, on the basis of reanalysis of existing studies, that panel studies increase the precision of estimates of differences in responses between two points of time, and that panel studies do not appear to introduce survey-resurvey bias, particularly if repeat surveys are at least 1 month apart. However, they noted there is a lack of consistency in this result among some of the surveys analyzed, and they suggested that panel studies should be strengthened by the addition of non-panel respondents in the repeat surveys.

The Stansfeld et al. (2001) review was prepared to provide evidence to inform a rapid prospective Health Impact Assessment for the Mayor of London's Ambient Noise Strategy. The report focused on non-auditory health impacts, causal pathways to explain health effects, and interventions that can improve health. Change studies were briefly reviewed in the context of a section dealing with interventions, but no specific mention was made of excess response or adaptation. The authors' conclusions with respect to annoyance and sleep disturbance were as follows.

- The literature on intervention studies is sparse.

- Intervention studies were of variable quality.

- Intervention such as noise barriers and reduction of road traffic noise levels at source by approximately $10 \mathrm{dBA}$ seem to decrease levels of annoyance in communities exposed to road traffic.

- Relatively few community studies assessing the impact of noise reduction on sleep have been conducted. Those studies that have been carried out with a reduction between 6 and $14 \mathrm{dBA}$ resulted in both subjective and objective improvements in sleep.

Huybregts (2003) reviewed seven previous studies of change in railway noise and concluded that there is no reason to doubt that, similar to other forms of transport noise, there is an excess response (he termed it an exaggerated community response) when railway noise exposure changes, though he suggested further work is needed to understand both magnitude and duration of the change effect.

\section{MORE RECENT CHANGE STUDIES}

A range of field studies of change has been conducted since the various reviews (see Tables I and II) and show similar diversity in study designs, and results as found in the earlier studies. Inclusion of some of the results from these later studies in the previous syntheses is possible.

Decibel-equivalent magnitudes of the change effect have been able to be estimated by the current authors by applying the same methodology used by Horonjeff and Robert (1997). These are included in Fig. 1. Two of the seven sites in the study Fidell et al. (2002) of change in aircraft noise levels experienced sufficient increase in exposure to allow decibelequivalent change effects to be estimated [we used the FICON (1992) exposure-response curve to estimate the change effect from the reported data]. Nilsson and Berglund (2006) and Öhrström (2004) reported studies of decrease in road traffic noise exposure, the first from the placement of a barrier, and the second from a reduction in traffic flow. These authors suggested that there was no excess response to the change indoors, but our reanalysis [using the Miedema and Oudshoorn (2001) and Miedema and Vos (1998) exposureresponse curves respectively] suggests that there was a large change effect at three of the "sites" (actually three "distance from road categories" - change in noise exposure of more distant categories could not be estimated from the paper) in the barrier study and at the one site in the traffic reduction study. Kastka et al. (1995a) revisited the barrier sites reported previously (Kastka and Paulsen, 1979), reporting new data and readjusting their steady-state exposure-response baseline. Kastka et al. (1995a) examined residents' responses in 1988 and 1976 to barriers that had been constructed after the first survey. We have calculated decibel-equivalent changes at their seven barrier sites (using their noise disturbance score and their before exposure-response relationship_Table 10 in Kastka et al. (1995a) — and these have also been shown in Fig. 1. At five of the sites, there is a small excess response, but an under response, one large, at two sites.

A recent longitudinal study of response to noise around Schiphol Airport incorporates the most comprehensive and purpose-designed study of change to date, though detailed results are not yet widely reported (Ministry of Transport, Public Works and Water Management, 2005). Surveys of effects of aircraft noise exposure were conducted around Schiphol in 1996, 2002, and 2005 (Houthuijs et al., 2007). A new runway at the airport was opened in February 2003, and a panel of 640 persons, whose exposure was likely to change as a result of the new runway, was selected from the 2002 survey group. This panel was resurveyed annually over the 2 $1 / 2$ years following the change, with half of the panel surveyed in northern hemisphere springs and half in autumns, giving six data points subsequent to the change (Breugelmans et al., 2007). In total, 478 respondents completed four panel interviews, one before the change and three after the change. The panel was made up of three subgroups: one experiencing an increase in exposure, one a decrease, and one as control experiencing negligible change. Results from the first (before change) panel round were used to derive a baseline exposure-response relationship based on noise exposure $\left(L_{\mathrm{den}}\right)$ over the previous 12 months.

Breugelmans et al. (2007) reported significant excess response for the subgroup experiencing the increase in exposure. Decibel-equivalent change effects have been estimated by the current authors based on the before-change exposureresponse relationship, and the trajectory of excess response for this subgroup over the six repeats is shown in Fig. 1. Excess response was observed from the second round of surveys and continued throughout the study. There was a drop in the penultimate round but a return to large excessresponse in the latest round. The subgroup experiencing the 
decrease in exposure, and the control group experiencing negligible change, did not exhibit excess response in any of the survey rounds.

This study was particularly notable in that, together with post-change longitudinal measurement of annoyance (and sleep disturbance and self-reported change in general health), longitudinal measurements were also made on a wide range of non-acoustical factors including living satisfaction, noise sensitivity, expectations about the airport, neighborhood quality and future noise levels, fear of aircraft crashes, and negative attitudes toward the airport. A generalized linear mixed model analysis found that the excess response was not diminished significantly when adjusted for all of the nonacoustic factors. The findings suggest that the change effect was driven primarily by the change in noise exposure.

Overall, these more recent studies show magnitudes of change effect excess response (Fig. 1) in line with those reported in the original synthesis by Horonjeff and Robert (1997).

Klæboe et al. (1998) also reported an excess response, with a decibel-equivalent change effect of 5-8 dB resulting from an area-wide reduction in noise exposure (and a reduction in other factors such as air pollution exposure) from traffic reductions affecting a whole town area in Oslo from 1987 to 1994/96. This result was the aggregate across all exposure levels $\left(50-75 L_{\mathrm{eq}, 24 \mathrm{~h}}\right.$, particularly those less than $70 L_{\mathrm{eq}, 24 \mathrm{~h}}$ ) but the results cannot be included in Fig. 1 as changes in noise exposure at individual sites were not reported.

Other observations from the more recent change studies include suggestions that expectation of increased annoyance had a noticeable effect on the level of annoyance before noise countermeasures were realized (Öhrström, 1997; Schreckenberg et al., 2001); a bypass achieving a mean reduction in noise of 2-4 $\mathrm{dB}$ produced no noticeable change in annoyance (Stansfeld et al., 2001) and suggestions that adaptation occurs soon after changes in noise exposure (Hatfield et al., 2001).

\section{DISCUSSION}

\section{A. Excess response to change}

\section{Airport studies and studies of gradual change in exposure}

As already noted by Horonjeff and Robert (1997), the results for the airport studies were, in general, quite different to those for the road studies. With the exception of our estimate of large excess response in the studies by Fidell et al. (2002) and by Breugelmans et al. (2007), the change effect in the airport studies was very small-in some cases, an under response-compared to the predominance of excess response in the road studies. While this may demonstrate a difference in response to change between aircraft noise and roadway noise, another, and perhaps more obvious, explanation is that the difference may be an artifact of the nature of the particular noise changes that occurred at most of the airports studied.

Horonjeff and Robert (1997) also noted that most of the airport studies they reviewed either involved temporary changes in noise exposures (Fidell et al., 1985; Raw and Griffiths, 1985; Gjestland et al., 1995) or small changes of 3 $\mathrm{dB}$ or less in noise exposure (Fidell and Jones, 1975; Fidell et al., 1985). Some airport change studies (Fidell et al., 1996; Kastka et al., 1995b) and some road change studies (Stansfeld et al., 2001) also had the acoustic characteristic of a gradual change in noise exposure. As Fields et al. (2000) previously noted, these are very different situations to where there is an abrupt or step change in exposure.

In summary, because of the potentially confounding effect of the limited magnitude and different nature of the changes that occurred in the various airport studies for which data are available, it would be inappropriate to draw conclusions from these studies about response to change around airports. Further studies involving change at airports that do not have these constraints [as, for example, the Schiphol study reported by Breugelmans et al. (2007) and Houthuijs et al. (2007)] will be necessary to examine whether there might be any difference between response to change for different transport modes. The same applies for situations, for any mode, for where there has been a gradual change in exposure as against a step-change.

\section{Type 2 changes}

Studies of both Type 1 and Type 2 changes were included in the reviews, and there is some evidence that people may respond differently in Type 2 changes, reporting less response and little or no change effect (Griffiths and Raw, 1986). Langdon and Griffiths (1982) re-examined the results of Kastka and Paulsen's (1979) longitudinal study of barriers and found under response, explaining this as due to the differential effect of noise reductions by barriers rather than reductions of the noise source. However, as noted above, using the new data for these sites from Kastka et al. (1995a), there was a small excess response at the majority of the sites (see Fig. 1) but an under response at two sites. Vincent and Champelovier (1993) reported that noise annoyance shows only a small reduction for a $9 \mathrm{~dB}$ drop of noise levels resulting from barrier construction at their one site, though, in fact, the reduction in percent highly annoyed appears generally in line with expected reductions from steady-state exposureresponse curves, that is, no excess response. No excess response to change was also suggested in the longitudinal study by Lambert (1978) of the effect of a single barrier. While Nilsson and Berglund (2006) reported no excess response in a barrier study, re-analysis by the current authors (Sec. V above) suggests that there was. Baughan and Huddart (1993) also noted that the change effect may not be present in Type 2 changes

While Fields et al. (2000) concluded that studies aimed at evaluating the effect of noise-shielding interventions (barriers, double glazing) rarely lead to findings of an excess response, evidence of the presence and direction of change effects in Type 2 studies to date is ambiguous. A reasonable conclusion at this stage is that the results of Type 1 and Type 2 studies should be separated in any future analysis of change studies given the mixed evidence above regarding excess response in Type 2 studies. 


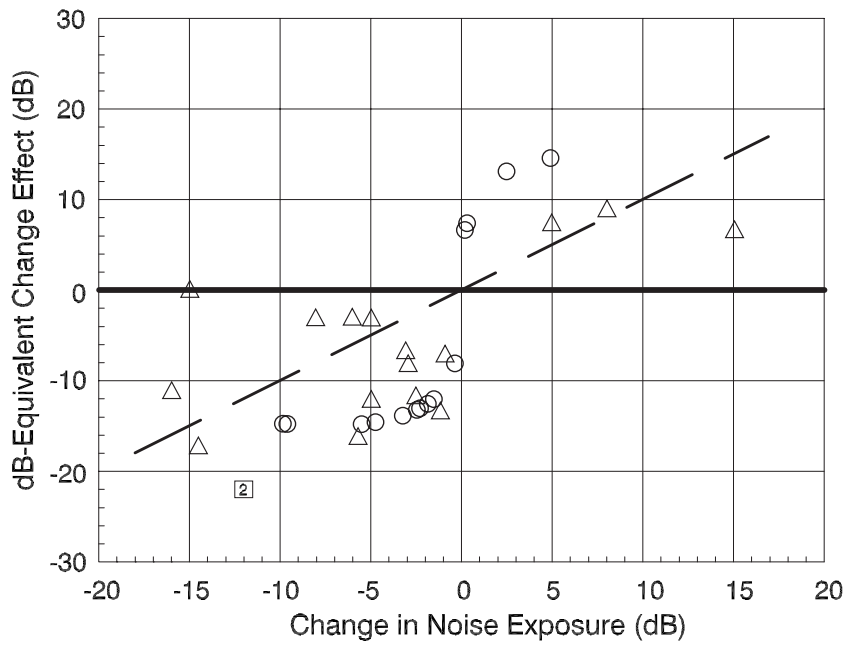

FIG. 2. Decibel-equivalent excess response change effect for Type 1 changes of road traffic sources only. The broken line indicates a change effect of the same magnitude (decibel-equivalent) as the change in noise exposure. Legend as in Fig. 1.

\section{Type 1 road changes}

Given the conclusions above regarding airport change studies, and Type 2 change studies, it is reasonable to examine a specific subset of the studies-those where the source was road traffic and where the nature of the change in exposure was Type 1 changes.

Figure 2 shows the same data set as Fig. 1, but deletes aircraft noise studies and Type 2 road studies where the noise exposure change occurred through modification of the transmission path-usually by the installation of barriers. The remaining studies are those where the change in noise exposure has resulted from changes in the road source itself-the construction of new roads, either as new sources or providing traffic relief on existing roads-or some other change in traffic flow. The weight of evidence from this subset of field studies is that there is an excess-response change effect in annoyance responses for these changes in noise exposure. All available studies demonstrate, with remarkable consistency, an excess response in situations of both increments and decrements of noise exposure: respondents whose noise exposure has increased report more annoyance than expected from steady-state studies; respondents whose noise exposure has decreased report less annoyance than expected from steady-state studies. The effect is present even for quite small changes in noise exposure.

The broken line shown in Fig. 2 is not a line of best-fit as we have chosen not to suggest a predictive relationship between noise change and its associated change effect from the studies reviewed-given the differences between the studies in terms of metrics and designs, and the approximations necessary to estimate the change effect from the data reported in them. The broken line indicates where the magnitude of the change effect is equal to the magnitude of the change in exposure. Figure 2 clearly shows that, in road studies with Type 1 changes, the excess-response change effect (decible-equivalent) tends to be greater (often much greater) than the change in noise level exposure itself.

\section{Annoyance versus activity interference in change responses}

The results reported in Fig. 2 are for annoyance responses. Several authors have found, or suggest, that activity interferences (speech interference, closing windows, etc.) may not display the same level of excess response as do annoyance measures when noise exposure changes.

Kastka et al. (1995a) found that interference effects of noise did not show the same change effects that were observed in annoyance scores in their longitudinal study of the effect of noise reduction by barriers. Klæboe et al. (1998) also provided evidence from their road traffic reduction study in Oslo that, while there was a significant excessresponse change effect for traffic noise annoyance, there was no similar systematic change effect in the reporting of disturbances/inconveniences from road traffic noise. Babisch and Gebhardt (1986) reported that there was no excess response to a reduction of some $11 \mathrm{~dB}$ in road traffic noise levels in inner city Berlin, 1.5 years after the change, as their result did not deviate from steady-state response data collected in Hamburg. However, as Klæboe et al. (1998) pointed out, this study had measured changes in interference activities only, not annoyance, and such a result is in line with the findings above of no observed excess response in activity interference. Breugelmans et al. (2007) also found no excess response in sleep disturbance, despite a large excess response in annoyance. However, Öhrström (2004) reported good correlations between reductions in annoyance scores and reductions in activity disturbances in her longitudinal study of a large decrease in road traffic noise exposure.

\section{B. Adaptation after the change}

Only a small number of recent studies contributed data tracking respondents' reactions for an extended period after the change. Griffiths and Raw $(1987,1989)$ extended a previous longitudinal study of response to reduced traffic noise (Griffiths and Raw, 1986). They found that some $40 \%$ of the large excess response to change they had originally measured 2 years after the reduction was still present 7-9 years after the change. Moehler et al. (1997) showed that annoyance reductions achieved by noise reductions through rail grinding still persisted in a third survey, 12 months after the initial survey following the noise reductions. Klæboe et al. (1998) reported similar exposure-response curves at two time periods (2 years apart), after area-wide improvements had reduced exposure, indicating persistence of the excessresponse change effect. In the longitudinal study at Schiphol airport, Breugelmans et al. (2007) reported no sustained adaptation in excess response to increased exposure over $21 / 2$ years after the change. There is thus no evidence from recent work to alter the conclusions reached by Horonjeff and Robert (1997), in their review of nine longitudinal studies, that there is little evidence that excess response attenuates within several years of the change.

\section{CONCLUSIONS}

Studies of human response to a change in noise exposure over 3 decades have produced results which suggest that hu- 
man response to change is not in line with what would be expected from steady-state exposure-response curves. Building on previous syntheses of change studies, this review concludes that a change effect of excess response to a stepchange in road traffic noise occurs in addition to the exposure effect. This occurs in noise annoyance responses though not in activity interference responses. Consistent evidence of a similar change effect for aircraft noise and railway noise changes is lacking but, rather than this indicating that human response to change is different between different transportation noise sources, we suggest that this may be a result of the nature of the noise changes available in most aircraft and railway noise change studies to date: generally small, gradual, or temporary.

A change effect is unequivocally present in the results of the road traffic noise studies where the intensity of the road traffic source changes through changes in traffic volume on the source roads (Type 1 changes). For these types of change situations, the decibel-equivalent magnitude of the excess responses (both the excess benefit arising from reductions in exposure and the excess disbenefits arising from increases in exposure) can be greater, often much greater, than the change in noise levels itself. For changes resulting from the insertion of barriers or other path mitigation interventions (Type II changes), the evidence for a change effect is not clear. The excess-response change effect does not appear to attenuate over time-even years after the change.

Further studies of change are required as many of the studies of change reviewed have been characterized by weak or inappropriate designs. The difficulty, of course, is to find "natural laboratories" where such change research can be conducted. It will only be through the careful design of change studies that it will be possible to unravel, and explain, this phenomenon, and provide decision makers with practical and quantitative advice on community response to changes in noise exposure. The presence, magnitude, and persistence of the excess response warrants consideration of a change effect in assessing the impact of infrastructure changes and in policy making with respect to such changes.

\footnotetext{
${ }^{1}$ While we refer to exposure-response relationships derived under these conditions as steady state curves, there is a caveat to this descriptor. We observe later in this paper that change effects are persistent; hence any previous change in exposure at a site should continue to influence the response of those long-term residents who had experienced the change, and thus be "mixed" with the response of other residents at the site who had moved in since any change in exposure. We examine some limited evidence on the differential response of long-term residents and newcomers in Brown and van Kamp (2009).

${ }^{2}$ While we use the preferred term excess response throughout this paper, where we are reviewing the work and results of other authors, it is often more appropriate to use the terminology they have adopted; most often over-reaction.

${ }^{3}$ The baseline response in any change study is the steady-state exposure response curve applicable to the sites in that study before change in exposure occurred. The origin of these baselines varied from study to study, ranging from local baseline exposure-response curves derived within the study itself, to control site exposure-response curves, to synthesized exposure-response curves (mostly Schultz, 1978)—see Horonjeff and Robert (1997) for full details. The baseline provides the datum from which change effects are estimated.
}

Anotec Consulting (2003). "Studies on current and future aircraft noise ex- posure at and around community airports. Summary for policy makers," Document No. PAN012-6-0.

Babisch, W., and Gebhardt, S. (1986). "Gestortheitsreaktionen durch Verkehrslamr-Eine 'vorher/nachher'-untersuchung. (Annoyance reactions caused by traffic noise-A 'before/after'-study)," ZfLärmbek. 33, $38-45$.

Baughan, C., and Huddart, L. (1993). "Effects of traffic noise changes on residents' nuisance ratings," in Proceedings of the Sixth International Congress on Noise as a Public Health Problem, Noise \& Man 1993, Nice, July, Vol. 2, pp. 585-588.

Breugelmans, O., Houthuijs, D., van Kamp, I., Stellato, R., van Wiechen, C., and Doornbos, G. (2007). "Longitudinal effects of a sudden change in aircraft noise exposure on annoyance and sleep disturbance around Amsterdam Airport," in Proceedings of the ICA, Madrid, Paper No. ENV-04002-IP.

Brown, A. L. (1987). "Responses to an increase in road traffic noise," J. Sound Vib. 117, 69-80.

Brown, A. L., Hall, A., and Kyle-Little, J. (1985). "Response to a reduction in traffic noise exposure," J. Sound Vib. 98, 235-246.

Brown, A. L., and van Kamp, I. (2009). "Response to a change in transport noise exposure: Competing explanations of change effects," J. Acoust. Soc. Am. 125, 905-914

EC/DG ENV (2002). "Directive 2002/49/EC of the European Parliament and of the Council of 25 June 2002 relating to the assessment and management of environmental noise," OJ L 189, 18.7.2002, EU Parliament, Brussels, pp. 12-25.

Egan, M., Petticrew, M., Ogilvie, D., and Hamilton, V. (2003). "New roads and human health: A systematic review," Am. J. Public Health 93, 14631471.

FICON (1992). Federal Agency Review of Selected Airport Noise Analysis Issues, Federal Interagency Committee on Noise, FICUN, Wahington, DC. Fidell, S., Barber, D., and Schultz, T. J. (1991). "Updating a dosage-effect relationship for the prevalence of annoyance due to general transportation noise," J. Acoust. Soc. Am. 89, 221-233.

Fidell, S., Horonjeff, R., Mills, J., Baldwin, E., Teffeteller, S., and Pearsons, K. (1985). "Aircraft annoyance at three joint air carrier and general aviation airports," J. Acoust. Soc. Am. 77, 1054-1068.

Fidell, S., and Jones, G. (1975). "Effects of cessation of late-night flights on an airport community," J. Sound Vib. 42, 411-427.

Fidell, S., Pearsons, K., Tabachnik, B. G., and Howe, R. (2000). "Effects on sleep disturbance of changes in aircraft noise near three airports," J. Acoust. Soc. Am. 107, 2535-2547.

Fidell, S., Silvati, L. and Haboly, E. (2002). "Social survey of community response to a step change in aircraft noise exposure," J. Acoust. Soc. Am. 111, 200-209.

Fidell, S., Silvati, L., and Pearsons, K. (1996). "On the noticeability of small and gradual declines in aircraft noise exposure levels," in Proceedings of Internoise 1996, Liverpool, UK, Book 5, pp. 2247-2252.

Fields, J. M. (1990). "Policy-related goals for community response studies," Environ. Int. 16, 501-514.

Fields, J. M. (1993). "Effect of personal and situational variables on noise annoyance in residential areas," J. Acoust. Soc. Am. 93, 2753-2763.

Fields, J. M. (1994). "A review of an updated synthesis of noise/annoyance relationships," NASA Report No. CR-194950, NASA Langley Research Center, Hampton, VA.

Fields, J. M., Ehrlich, G. E., and Zador, P. (2000). "Theory and design tools for studies of reactions to abrupt changes in noise exposure," NASA Report No. CR-2000-210280, NASA Langley Research Center, Hampton, VA.

Gjestland, T., Liasjø, K., and Granøien, I. (1995). "Community response to noise from short-term military aircraft exercises," J. Sound Vib. 182, 221228 .

Gjestland, T., Liasjø, K., Granøien, I., and Fields, J. M. (1990). "Response to noise around Oslo Airport Fornebu," DELAB Report No. STF40 A90189, Civil Aviation Administration, Oslo.

Griffiths, I. D., and Raw, G. J. (1986). "Community and individual response to changes in traffic noise exposure," J. Sound Vib. 111, 209-217.

Griffiths, I. D., and Raw, G. J. (1987). "Community and individual response to changes in traffic noise exposure," in Environmental Annoyance: Characterization, Measurement, and Control, edited by H. S. Koelega (Elsevier, Amsterdam), pp. 333-343.

Griffiths, I. D., and Raw, G. J. (1989). "Adaptation to changes in traffic noise exposure," J. Sound Vib. 132, 331-336.

Guski, R. (2004). "How to forecast community annoyance in planning noisy 
facilities," Noise Health 6, 59-64.

Hatfield, J., Job, R. F. S., Carter, N. L., Peploe, P., Taylor, R., and Morell, S. (1998b). "Attitude-mediated reaction to noise influences physiological responses: Evidence supporting causality," in Proceedings of Internoise 1998, Christchurch, New Zealand, Paper No. 440.

Hatfield, J., Job, R. F. S., Carter, N. L., Peploe, P., Taylor, R., and Morell, S. (2001). "The role of adaptation in responses to noise exposure: Comparison of steady state with newly high noise areas," in Proceedings of the Fourth European Conference on Noise Control, Euronoise PATRA, January.

Hatfield, J., Job, R. F. S., Peploe, P., Carter, N. L., Taylor, R., and Morell, S. (1998a). "Demographic variables may have a greater modifying effect on reaction to noise when noise exposure changes," in Proceedings of the Noise Effects 1998, Seventh International Congress on Noise as a Public Health Problem, Sydney, Vol. 2, pp. 527-530.

Horonjeff, R. D., and Robert, W. E. (1997). "Attitudinal response to changes in noise exposure in residential communities," NASA Report No. CR-97205813, National Aeronautics and Space Administration, Washington, DC. Houthuijs, D., Breugemans, O., van Kamp, I., and van Wiechen, C. (2007). "Burden of annoyance dues to aircraft noise and non-acoustical factors," in Proceedings of Internoise 2007, Istanbul, Paper No. 838472.

Huybregts, C. (2003). "Community response to changes in railway noise exposure-A review," in Proceedings of Wespac VIII, Melbourne, Australia, April.

ISO/TS 15666:2003 Acoustics-Assessment of noise annoyance by means of social and socio-acoustic surveys (2003).

Job, R. F. S. (1988). "Over-reaction to changes in noise exposure: The possible effect of attitude," J. Sound Vib. 126, 550-552.

Job, R. F. S., Topple, A., Carter, N. L., Peploe, P., Taylor, R., and Morell, S. (1996). "Public reactions to changes in noise levels around Sydney Airport," in Proceedings of Internoise 1996, Liverpool, UK, Book 5, pp. 2419-2424.

Jonsson, E., and Sörensen, S. (1973). "Adaptation to community noise-A case study," J. Sound Vib. 26, 571-575.

Kastka, J. (1981). "Zum Einfluss verkehrsberuhigender maßnahmen auf lärmbelastung und lärmbelästigung (The influence of traffic calming measures on noise load and noise annoyance)," ZfLärmbek 28, 25-30.

Kastka, J., Borsch-Galetke, E., Guski, R., Krauth, J., Paulsen, R., Schuemer, R., and Oliva, C. (1995b). "Longitudinal study on aircraft noise effects at Düsseldorf airport 1981-1993," in Proceedings of the 15th ICA, Trondheim, Vol. IV, pp. 447-451.

Kastka, J., Buchta, U., Ritterstaedt, R., Paulsen, R., and Mau, U. (1995a). "The long term effect of noise protection barriers on the annoyance response of residents," J. Sound Vib. 184, 823-852.

Kastka, J., and Paulsen, R. (1979). "Untersuchung über die subjektive und objektive wirksamkeit von schallschutzeinrichtungen und ihre nebenwirkungen auf die anlieger (A study into the subjective and objective effectiveness of noise barriers and their side effects on residents)," Institut für Hygiene, Universität Düsseldorf.

Klæboe, R., Engelien, E., and Steinnes, M. (2006). "Context sensitive noise impact mapping," Appl. Acoust. 67, 620-642.

Klæboe, R., Kolbenstvedt, M., Lercher, P., and Solberg, S. (1998). "Changes in noise reactions-Evidence for an area effect?," in Proceedings of Internoise 1998, Christchurch, New Zealand, pp. 16-18.

Lambert, J., Champelovier, P., and Vernet, I. (1996). "Annoyance from high speed train noise: A social survey," J. Sound Vib. 193, 21-28.

Lambert, J., Champelovier, P., and Vernet, I. (1998). "Assessing the railway bonus: The need to examine the "new infrastructure' effect," in Proceedings of Internoise 1998, Christchurch, New Zealand.

Lambert, J., Champelovier, P., Vernet, I., Annequin, C., and Baez, D. (1994). "Community response to high speed train noise in France," in Proceedings of Internoise 1994, Yokohama, pp. 125-128.

Lambert, R. F. (1978). "Experimental evaluation of a freeway noise barrier," Noise Control Eng. 11, 86-94.

Langdon, F. J., and Griffiths, I. D. (1982). "Subjective effects of traffic noise exposure, II. Comparisons of noise indices, response scales and the effects of changes in noise levels," J. Sound Vib. 83, 171-180.

Mackie, M., and Davies, C. H. (1981). "Environmental effects of traffic change," TRRL Laboratory Report No. 1015, Transport and Road Research Laboratory, Crowthorne, UK.

Mehra, S. R., and Lutz, C. (2000). "Berechnung und subjective wahrneh- mung der lärmpegeländerung aufgrund einer neu erstellten umgehungsstraße (Measurement and subjective perception of noise level changes due to a new roadway)," ZfLärmbek 47, 58-67.

Miedema, H. M. E., and Oudshoorn, C. G. M. (2001). "Annoyance from transportation noise: Relationships with exposure metrics DNL and DENL and their confidence intervals," Environ. Health Perspect. 109, 409-416.

Miedema, H. M. E., and Vos, H. (1998). "Exposure response relationships for transportation noise," J. Acoust. Soc. Am. 104, 3432-3445.

Ministry of Transport, Public Works and Water Management (2005). "Evaluatie Schipholbeleid: Schiphol beleefd door omwonenden (Evaluation Schiphol: Schiphol perceived by its residents)," Directorate-General Transport and Aviation

Mital, A., and Ramakrishnann, A. S. (1997). "Effectiveness of noise barriers on an interstate highway: A subjective and objective evaluation," J. Hum. Ergol (Tokyo) 26, 31-38.

Moehler, U., Hegner, A., Schuemer, R., and Schuemer-Kohrs, A. (1997). "Effects of railway-noise reduction on annoyance after rail-grinding, in Proceedings of Internoise 1997, Budapest, Vol. II, pp. 1021-1026.

Nilsson, M. E., and Berglund, B. (2006). "Noise annoyance and activity disturbance before and after the erection of a roadside noise barrier," J. Acoust. Soc. Am. 119, 2178-2188.

Nimura, T., Sone, T., and Kono, S. (1973). "Some considerations on noise problem of high-speed railway in Japan," in Proceedings of Internoise 1973, Copenhagen, pp. 298-307.

Öhrström, E. (1997). "Community reactions to railway traffic-effects of countermeasures against noise and vibration," in Proceedings of Internoise 1997, Budapest, pp. 1065-1070.

Öhrström, E. (2004). "Longitudinal surveys on effects of changes in road traffic noise-annoyance, activity disturbances, and psycho-social wellbeing," J. Acoust. Soc. Am. 115, 719-729.

Öhrström, E. and Skånberg, A. (2000). "Adverse health effects in relation to noise mitigation-A longitudinal study in the city of Göteborg," in Proceedings of Internoise 2000, Nice, Vol. 4, pp. 2112-2115.

Raw, G. J., and Griffiths, I. D. (1985). "The effect of changes in aircraft noise exposure (Letter to the editor)," J. Sound Vib. 101, 273-275.

Richard, J., and Richter-Richard, H. (1984). "Erfahrungen mit dem einsatz verkesrsberuhigender massnahmen zur larmminderung (Experiences from traffic calming measures to reduce noise loads)," ZfLärmbek. 31, 11-14.

Schreckenberg, D., and Meis, M. (2007). "Noise annoyance around an international airport planned to be extended," in Proceedings of Internoise 2007, Istanbul, Turkey.

Schreckenberg, D., Schuemer, R., and Moehler, U. (2001). "Railway-noise annoyance and 'misfeasance' under conditions of change," in Proceedings of Internoise 2001, The Hague, The Netherlands, Paper No. 344.

Schuemer, R., and Schreckenberg, D. (2000). "Anderung der larmbelastung bei massnahme bedingter stufenweise veranderter gerauschbelastungHinweise auf einige befunde und interpretationsansatze (The effect of stepwise change of noise exposure on annoyance)," ZfLärmbek. 47, 134143

Schultz, T. J. (1978). "Synthesis of social surveys on noise annoyance," J. Acoust. Soc. Am. 64, 377-405.

Stansfeld, S. A., Haines, M. M., Curtis, S. E., Brentnall, S. L., and Brown, B. (2001). Rapid Review on Noise and Health for London (St. Bartholmew's and the Royal London School of Medicine and Dentistry, Queen Mary, University of London, London).

Vallet, M. (1996). "Annoyance after changes in airport noise environment," in Proceedings of Internoise 1996, Liverpool, UK, Vol. 5, pp. 2329-2335. Van Dongen, J. E. F., and van den Berg, R. (1983). "De gewenning aan het geluid van een nieuwe spoorlijn (Getting used to noise from a new railway line)," Report No. RL-HR-03-02, Ministry of Housing, Spatial Planning and the Environment, The Hague.

Van Kempen, E. E. M. M., and van Kamp, I. (2005). "Annoyance from air traffic noise. Possible trends in exposure-response relationships," Report No. 01/2005 MGO Evk, RIVM, Bilthoven, The Netherlands.

Vincent, B., and Champelovier, P. (1993). "Changes in the acoustic environment: need for an extensive evaluation of annoyance," in Proceedings Noise and Man 1993, Sixth International Congress on Noise as a Public Health Problem, Vol. 2, pp. 425-428.

Weinstein, N. D. (1982). "Community noise problems: Evidence against adaptation," J. Environ. Psychol. 2, 87-97. 